\title{
MAKNA BUDAYA LAGU DOLANAN: DHONDHONG APA SALAK, GUNDHUL PACUL
}

\author{
Arini Hidayah \\ Program Studi Sastra Inggris, Fakultas Bahasa dan Sastra, Universitas Surakarta \\ J1. Raya Palur Km 5 Surakarta (57772), Tlpn. 0271-825117 \\ Email: arini.hidayah@mail.ugm.ac.id
}

\begin{abstract}
ABSTRAK
Lagu dolanan Jawa Tengah, dhondhong apa salak dan gundhul pacul, mempunyai perananyang penting untuk anak-anak karena di dalam lagu dolanan tersebut terdapat nilai-nilai pendidikan dan simbol-simbol kehidupan yang dapat dijadikan tuntunan untuk anak-anak. Penelitian ini akan menggali makna budaya yang tersembunyi di dalam lagu dolanan Jawa Tengah yakni dhondhong apa salak, gundhul pacul, dan kupu kuwi agar menemukan pemahaman budaya Jawa Tengah yang tersirat dalam lagu dolanan tersebut. Metode pengambilan data dalam makna budaya lagu dolanan di Jawa Tengah dengan cara interview atau wawancara secara personal yakni mewawancarai 3 informan. Model memvalidasi data ini mengarahkan peneliti mengambil data harus menggunakan beragam sumber data yang berbeda-beda. Lagu dolanan di Jawa Tengah seperti dhondhong apa salak, gundhul pacul, dan kupu kuwi mempunyai makna budaya yang baik dalam pendidikan maupun kehidupan anakanak. Lagu dolanan dhondhong apa salak mempunyai makna budaya yakni karakter manusia ada 3 diilustrasikan seperti buah dhondhong, salak, dan duku. Sifat yang paling baik diantara ke tiga ilustrasi tersebut yaitu buah duku karena sifat luar dan dalam sama-sama baik, halus, dan lembut. Lagu dolanan gundhul pacul mengandung makna budaya yaitu jika orang yang mempunyai kehormatan, kedudukan, dan kemuliaan janganlah menjadi sombong karena Allah dapat memberikan balasaan yang setimpal karena kesombongannya. Sedangkan, lagu dolanan kupu kuwi juga mengandung makna budaya yakni bagaimana manusia mendapatkan kebahagiaan, kebahagiaan itu tidak bisa diprediksi kapan datangnya, kapan munculnya, dan arah mana kebahagiaan akan muncul.
\end{abstract}

Kata-kata Kunci: Lagu Dolanan Jawa Tengah, Makna Budaya, Dhodhong Apa Salak, dan Gundhul Pacul

\section{ABSTRACT}

Central Java nursery rhyme: 'dhondong apa salak' and 'gundhul pacul' have important roles for children because they contain education value and the symbols of life that can be such guidance for children. This research is to dig the meaning of culture lies in the central Java play songs, they are dhondong apa salak and gundhul pacul to find out the understanding of Central Java culture that arise in those Play Songs. The Method of the collecting data of this research is by using personal interview, there are three informants involved. The data validity leads the researcher to use various data source. Play songs in Central Java like 'dhondong apa 
salak' and 'gundhul pacul' have cultural meaning that is well for both education and children life. The play song of 'dhondong apa salak' has cultural meaning that shows human characterization, there are three illustrations such as 'dhondong', 'salak', and 'duku'. The best characteristic among the three illustrated fruit is 'duku'because both inside and outside part of the fruit have well performance, soft, and smooth. 'Gundhul pacul' nursery rhyme contains cultural meaning if one has honor, position, and noble, never be conceited because God may give reprisal for his arrogance.

Keywords: Play Songs in Central Java, Culture Meaning, Dhondhong Apa Salak, and Gundhul Pacul

\section{PENDAHULUAN}

Linguistik antropologis (Foley, 2001) adalah cabang linguistik yang mempelajari bahasa dalam konteks sosial dan budaya yang lebih luas. Linguistik antropologis mencoba mencari makna tersembunyi di balik pemakaian bahasa, pemakaian bentuk-bentuk bahasa yang berbeda, pemakaian register, dan gaya. Linguistik antropologis merupakan disiplin interpretif yang mengupas bahasa untuk mendapatkan pemahaman budaya.

Indonesia mempunyai berbagai macam budaya, salah satunya budaya Jawa. Budaya Jawa mempunyai ciri khas yang dapat menunjukkan identitas kebudayaan daerah itu sendiri. Lagu dolanan adalah salah satu budaya yang dimiliki di daerah Jawa. Pulau Jawa sendiri terdiri dari tiga propinsi terdiri dari Jawa Barat, Jawa Timur, dan Jawa Tengah. Setiap propinsi mempunyai lagu dolanan sendiri-sendiri yang dapat diidentifikasikan melalui bentuk bahasa pada lirik lagu dolanan tersebut.

Dibia (2000) berpendapat bahwa lagu dolanan merupakan: bagian dari budaya tradisi, model pengembangan bangsa dalam memasuki globalisasi, salah satu warisan budaya bangsa dalam memasuki globalisasi, salah satu warisan budaya bangsa yang patut dilestarikan karena mempunyai fungsi yang amat penting bagi dunia pendidikan anak. Lagu dolanan termasuk tradisi lisan yang biasanya dilakukan secara spontan di halaman rumah, lorong, atau tempat terbuka lainnya.

Lagu dolanan Jawa mempunyai peranan yang penting untuk anak-anak karena di dalam lagu dolanan tersebut terdapat nilai-nilai pendidikan dan simbol-simbol kehidupan yang dapat dijadikan tuntunan untuk anak-anak. Nilai-nilai pendidikan dan simbol-simbol kehidupan tersebut dapat dilihat melalui makna budaya yang terdapat pada lagu dolanan Jawa. Lagu dolanan Jawa harus dipertahankan pada zaman sekarang ini karena lagu dolanan Jawa sekarang mulai tergerus akan lagu anak-anak modern yang berbahasa Indonesia yang isi lirik lagunya kebanyakan mengandung tentang percintaan antara anak laki-laki dan perempuan. Oleh sebab itu penulis mengangkat topik lagu anak-anak dalam kajian linguistik antropologis. Pada makalah ini akan menggali makna budaya yang tersembunyi di dalam lagu dolanan Jawa agar mendapatkan pemahaman budaya Jawa. Objek yang akan dibahas dalam makalah ini yaitu lagu dolanan yang terdapat pada propinsi Jawa Tengah. Pada makalah ini akan membahas 2 lagu dolanan Jawa Tengah yakni dhondhong apa salak dan gundhul pacul yang diambil dari buku yang berjudul "Gending-Gending Dolanan" karangan Widodo (2001). Buku tersebut disusun dengan tujuan sebagai sumber referensi Pendidikan Kesenian khususnya Sekolah Dasar maupun Sekolah Lanjutan Tingkat Pertama dan untuk melestaraikan lagu-lagu dolanan daerah yang banyak mengandung pesan pendidikan bagi generasi muda sekarang. 
Linguistik antropologis (Foley, 2001) adalah cabang linguistik yang mempelajari bahasa dalam konteks sosial dan budaya yang lebih luas. Linguistik antropologis mencoba mencari makna tersembunyi di balik pemakaian bahasa, pemakaian bentuk-bentuk bahasa yang berbeda, pemakaian register, dan gaya. Sedangkan Kridalaksana (2011) menyebutkan bahwa etnolinguistik juga disebut linguistik antropologi yang artinya cabang linguistik yang menyelidiki hubungan bahasa sikap bahasawan terhadap bahasa, salah satu aspek etnolinguistik yang sangat menonjol adalah masalah relativitas bahasa. Relatifitas bahasa adalah salah satu pandangan bahwa bahasa seseorang menentukan pandangan dunianya melalui kategori gramatikal dan klasifikasi semantik yang ada dalam bahasa itu dan yang dikreasi bersama kebudayaannya.

Pada penelitian ini, 2 lagu dolanan di Jawa Tengah (yakni dhondhong apa salak, gundhul pacul, dan kupu kuwi) akan menganalisis makna budaya yang terdapat pada lagu dolanan di Jawa Tengah melalui bahasa. Jadi topik kajian pada penelitian ini termasuk kajian linguistik antropologis karena dapat mengetahui kebudayaan masyarakat Jawa melalui dari segi bahasa dalam lirik lagu dolanan Jawa Tengah tersebut.

Darsono (1995) menyebutkan bahwa lagu atau dalam masyarakat Jawa sering sisebut tembang yang dapat diartikan sebagai lelagoning tembung (kalimat yang dilagukan dengan suara manusia), pupuh, tabuh gitik, dan kidung. Tembang atau lagu dolanan juga disebut lelagon yaitu penyusunannya bebas tidak terikat oleh aturan-aturan (gatra, guru lagu, dan guru wilangan). Dalam Pendekatan stilistik dalam 'Tembang Dolanan' (Suciati: 2001) mengemukakan bahwa lagu dolanan mengacu pada lagu-lagu Jawa, meskipun secara tersurat tidak tercantum kata anak-anak dan Jawa pada kata lagu dolanan tersebut. Supanto (1982) menjelaskan lagu dolanan adalah lagu-lagu yang dinyanyikan oleh anak-anak, baik dengan iringan atau tanpa iringan gamelan dan baik dengan gerakan atau tanpa gerakan yang syairsyairnya diserasikan dengan alam fikiran dan imaginasi anak-anak.

Suyani (2012) berpendapat bahwa kata lagu dolanan Jawa menunjuk pada sebuah objek yaitu lagu-lagu atau nyanyian yang digunakan untuk mengiringi sebuah atraksi permainan Jawa. Dolanan (permainan) merupakan kegiatan yang dilakukan dengan spontan dan dalam suasana riang gembira. Jadi dalam kegiatan bermain anak harus merasa senang. Jika suatu kegiatan, meskipun permainan, kalau anak tidak merasa senang, berarti tidak lagi bisa disebut permainan, melainkan sudah termasuk dalam kategori bekerja (melakukan pekerjaan). Kata Jawa dalam pengertian umum bisa menunjuk nama sebuah pulau, nama sebuh etnis atau suku bangsa, atau nama sebuah bahasa. Kata Jawa dalam tulisan ini dibatasi dalam pengertian bahasa, yaitu lagu dolanan yang diungkapkan dalam bahasa Jawa. Dari pengertian-pengerian di atas, dapat disimpulkan bahwa lagu dolanan di Jawa Tengah yaitu lagu-lagu atau nyanyian atau tembang berbahasa Jawa yang digunakan untuk mengiringi sebuah kegiatan permainan anak-anak khususnya di propinsi Jawa Tengah.

Pateda (2001) dalam 'Semantik Leksikal' mengemukakan bahwa makna leksikal adalah makna kata ketika kata itu berdiri sendiri, entah dalam bentuk leksem atau bentuk berimbuhan yang maknanya kurang lebih tetap, seperti yang dapat dibaca dalam kamus bahasa tertentu. Abdullah (2008) menyebutkan bahwa makna budaya adalah ungkapantambahan yang merupakan proses perluasan dan pergeseran makna semantik. Salah satu proses perluasan tersebut adalah metafora.

\section{METODE PENELITIAN}

Penelitian ini termasuk jenis penelitian deskriptif kualitatif. Jenis penelitian deskriptif kualitatif yaitu penelitian yang mencatat dengan teliti dan cermat data yang berwujud kata-kata, 
kalimat-kalimat wacana, gambar-gambar atau foto, catatan harian, memorandum, video-tape (Subroto, 1992). Dalam penelitian ini, untuk mengambil sumber data dalam makna budaya lagu dolanan di Jawa Tengah yakni terdiri dari tiga informan: Drs. Imam Sutardjo, M.Hum (Dosen Jurusan Sastra Jawa Universitas Negeri Surakarta sekaligus Dalang Wayang Kulit (Budayawan Jawa)), Nurnaningsih, S.S., M.Hum, dan Adi Deswijaya, S.S., M.Hum (beliau berdua adalah Dosen Pendidikan Bahasa dan sastra Jawa Fakultas dan Keguruan dan Ilmu Pendidikan Universitas Veteran Bangun Nusantara Sukoharjo). Metode pengambilan data dalam makna budaya lagu dolanan di Jawa Tengah dengan cara interview atau wawancara personal. Prosedur dalam wawancara personal biasanya pewawancara menyiapkan pedoman wawancara yang berisikan beberapa pertanyaan yang akan ditanyakan dan menyiapkan dalat untuk merekam informasi-informasi yang ingin dicari dari informan (Scheaffer et al, 1990).

Menurut Sutopo (2006) triangulasi merupakan cara yang paling umum digunakan bagi peningkatan validitas data dalam penelitian kualitatif. Dalam kaitannya dengan hal ini, dinyatakan bahwa terdapat empat macam teknik triangulasi, yaitu (1) triangulasi data/sumber (data triangulation), (2) triangulasi peneliti (investigator triangulation), (3) triangulasi metodologis (methodological triangulation), dan (4) triangulasi teoritis (theoretical triangulation). Pada dasarnya triangulasi ini merupakan teknik yang didasari pola pikir fenomenologi yang bersifat multiperspektif. Artinya untuk menarik kesimpulan yang mantap, diperlukan tidah hanya dari satu sudut pandang saja. Model memvalidasi data ini mengarahkan peneliti mengambil data harus mengguanakan beragam sumber data yang berbeda-beda. Artinya data yang sama atau sejenisakan lebih mantap kebenarannya apabila dari beberapa sumber data yang berbeda. Oleh karena itu triangulasi data sering disebut sebagai triangulasi sumber.

\section{HASIL DAN PEMBAHASAN}

Dari hasil wawancara ke tiga informan yakni Drs. Imam Sutardjo,M.Hum, Nurnaningsih, S.S., M.Hum, dan Adi Deswijaya, S.S tentang makna lagu dolanan di Jawa Tengah (dhondhong apa salak dan gundhul pacul) dapat didiskripsikan dalam sebagai berikut.

\section{Makna Budaya Lagu Dolanan "Dhondhong Apa Salak"}

Menurut Drs. Imam Sutardjo,M.Hum, dilihat dari segi fisik dhondhong mempunyai tekstur luar yang halus tapi isi buahnya sangat kasar, hal ini menandakan bahwa ada karakter manusia yang dilihat dari luar sikapnya halus tapi dalam hatinya sangat kasar. Salak jika dilihat dari segi fisik kulitnya sangat kasar tapi dalamnya halus, hal ini menandakan bahwa ada karakter manusia yang dari luar itu sangat kasar tapi hatinya halus. Duku mempunyai tekstur halus baik di dalam buah duku maupun kulitnya, hal ini menandakan bahwa ada perbuataan atau sikap dan dalam hati manusia sama-sama halus.

Gendong berarti memanfaatkan seseorang untuk melakukan sesuatu. Mbecak berarti membayar orang untuk melakukan sesuatu. Mlaku berarti berjalan sendiri, mandiri, tidak mau merugikan orang lain. Makna dari adhik ndherek ibu tindak menyang pasar yaitu seorang ibu harus memberikan perhatian lebih, dapat mengontrol, dan mengawasi anaknya. Seorang anak kalau ingin ikut dengan ibunya atau orang tua harus tidak boleh nakal dan tidak boleh menuntut sesuatu yang berlebihan. Kalau seorang anak tidak nakal,tidak menuntut sesuatu yang berlebihan, dan bersikap baik kepada ibu atau orang tua maka seorang ibu akan memberikan sesuatu penghargaan kepada anaknya.

Numaningsih, S.S., M.Hum menggambarkan bahwa secara fisik dhondhong mempunyai kulit halus dan bijinya kasar, hal ini mewujudkan bahwa sifat manusia dilihat dari luar halus tapi dalam hatinya kasar. Salak mempunyai kulit yang kasar dan bijinya halus, hal ini menunjukkan 
bahwa sifat manusia ada yang dari luar itu kasar dan mempunyai hati yang lembut. Duku mempunyai kulit dan biji yang halus, bisa diibaratkan bahwa watak manusia baik diluar maupun di dalam (hati) yakni sama lembutnya. Gendong berarti kalau bekerja menyusahkan orang, kalau yang minta digendong orangnya gemuk malah sulit. Mbecak berarti memperkerjakan orang lain dan memberi upah kepada orang yang yang berkerja tadi, di sisi lain orang yang dapat menelong seseorang dan di sisi lain menyusahkan orang lain. Mlaku maksudnya ekonomiss atau ekonomis, dan tidak mau meminta bantuan orng lain, di sisi lain selain mandiri, dengan berjalan maka badannya akan sehat. Maksud dari adhik ndherek ibu tindak menyang pasar yakni seorang anak ikut kepada orang tua tidak sekedar ikut saja tapi mau membantu ibu dalam hal apapun. Seorang ibu juga harus memberikan waktu lebih, menasehati, dan mengontrol anaknya. Seorang anak harus berbuat baik, tidak boleh menentang, dan tidak boleh menyakiti ibu atau orang tuanya. Jika seorang anak tidak nakal,tidak rewel menuntut sesuatu, dan taat kepada ibu atau orang tua maka ibu atau orang tua akan memberikan hadiah kepada anaknya.

Adi Deswijaya, S.S., M.Hum menyatakan bahwa makna dari segi fisik kulit dhondhong halus tapi isi buahnya kasar, hal ini menunjukkan bahwa ada perilaku manusia lembut dan halus, tapi dilihat dari hatinya, hatinya sangat kasar. Kulit Salak sangat kasar dan isinya halus, hal ini menandakan bahwa perilaku manusia dari luar kasar tapi hatinya halus, lembut, dan baik. Kulit Duku itu halus baik di dalam maupun di dalam, hal ini mewujudkan bahwa sifat manusi baik dalam maupun fifat hatinya yakni sama-sama halus, lembut, dan baik. Maksud Gendong berarti memberikan beban kepada seseorang untuk melakukan sesuatu. Mbecak berarti memberikan beban kepada orang lain dan memberikan uang kepada orang yang dibebani pekerjaan itu. Mlaku maksudnya berjalan mandiri dan tidak mau merepotkan orang lain. Arti dari adhik ndherek ibu tindak menyang pasar yaitu seorang anak harus selalu dinasehatin, diawasi, dididik, dan dikasih sayangin oleh ibu maupun orang tua. Seorang anak tidak boleh berbuat buruk, tidak boleh banyak menuntu, dan taat kepada ibu maupun orang tuanya. Apabila seorang anak berbuat baik dan berbakti kepada ibu atau orang tua maka ibu atau orang tua akan memberikan sesuatu yang disukai oleh anaknya.

Dari ketiga informan dalam pemaknaan makna budaya lirik lagu dolanan "Dhondong Apa Salak" bisa disimpulkan bahwa dhondhong mempunyai tekstur luar yang halus tapi isi buahnya sangat kasar, hal ini mewujudkan bahwa sifat manusia dilihat dari luar sikapnya halus tapi dalam hatinya sangat kasar. Salak mempunyai tekstur kasar dari luar tetapi tekstur dalamnya halus, hal ini menenunjukkan bahwa sifat manusia dari luar itu sangat kasar tapi hatinya halus. Buah duku mempunyai tekstur halus baik isi duku maupun kulitnya, hal ini menandakan bahwa sikap, perbuatan, dan dalam hati manusia sama-sama halus, lembut,dan baik. Gendong berarti memanfaatkan tenaga atau memberikan beban kepada seseorang untuk melakukan sesuatu. Mbecak maksudnya memanfaatkan tenaga dan membebani seseorang untuk bekerja dan tidak lupa memberikan uang kepada orang tersebut. Mlaku maksudnya seseorang yang dapat mengerjakan sesuatu dengan mandiri dan tidak mau merepotkan orang lain. Makna budaya adhik ndherek ibu tindak menyang pasar yaitu seorang anak harus dikntrol, dididik, diberi kasih sayang, dan dinasehatin oleh ibu agar anaknya kelak bisa dijadikan harapan bagi orang tua. Seorang anak harus bisa bersikap baik, menurut, taat, tidak boleh menantang, tidak boleh menuntut berlebihan kepada ibu ataupun orang tua. Jika seorang anak berbuat baik, tidak nakal, tidak meminta sesuatu yang berlebihan, taat, dan menurut kepada ibu atau orang tua, maka anak tersebut pantas mendapat hadiah atau penghargaan dari ibu atau orang tuanya.

\section{Makna Budaya Lagu Dolanan “ Gundhul Pacul”}

Menurut Drs. Imam Sutardjo,M.Hum bahwa Gundhul yang artinya tidak mempunyai rambut di kepala maksudnya orang yang tidak mempunyai kehormatan, kehormatan disini 
biasanya disimbolkan dengan rambut. Secara fungsinya pacul adalah alat untuk mencangkul tanah, maksudnya yaitu mencari nafkah. Gembelengan artinya sombong, berbuat seenaknya sendiri. Nyunggi maksudnya seseorang harus hati-hati dalam mengerjakan sesuatu. Wakul itu untuk wadah atau tempat nasi berarti wakul disini dalam mengumpulakan nafkah. Nyunggi wakul berarti harus berhati-hati dalam mengurus hal keuangan. Gembelengan artinya sombong, berbuat seenaknya sendiri. Jadi karena orang yang berbuat sombong dan berbuat seenaknya sendiri maka orang tersebut akan jatuh dari tahtanya. Maksudnya orang yang berbuat seenaknya sendiri dan mempunyai sifat sombong mengalami pembalasan dari Allah dengan memberikan suatu bencana yang mana membuat kerugian yang besar pada orang tersebut, hal ini diibaratkan pada wakul nglimpang. Orang yang mengalami kerugian bisa saja tidak hanya orang tersbut saja, mungkin bisa meluas kepada orang-orang yang disekitarnya, hal ini diibaratkan pada nglimpang segane dadi sak latar.

Numaningsih, S.S., M.Hum menggambarkan bahwa gundhul maksudnya orang yang kehilangan kehormatan. Pacul disini biasanya tertuju pada alat pertanian yakni pacul diartikan sebagai mencari nafkah untuk memenuhi keingianannya atau kehidupannya. Gembelengan maksudnya orang yang mempunyai hati yang congkak, sombong, berbuat sesuka hati, dan tidak peduli kepada orang lain. Maksud dari nyunggi yakni seseorang harus berhati-hati dalam mengerjakan suatu hal. Wakul itu tempat nasi dapat diartikan sebagai hasil-hasil jerih payag dalam mencari nafkah. Makna nyunggi wakul yakni mengambil sikap kehati-hatian dalam hal mengurus keuangan. Gembelengan maksudnya orang yang mempunyai hati yang congkak, sombong, berbuat sesuka hati, dan tidak peduli kepada orang lain. Karena orang yang mempunyai hati yang congkak, sombong, berbuat sesuka hati, dan tidak peduli kepada orang lain maka orang tersebut akan jatuh, tidak manfaat usahanya selama ini. Orang yang mempunyai hati yang congkak, sombong, berbuat sesuka hati, dan tidak peduli kepada orang lain maka orang tersebut dijatuhkan oleh Allah sebagai hukuman jatuh dari kehormatan atau kemuliaan akan perbuatan-perbuatan dahulu yang dia lakukan yang diilustrasikan wakul ngilmpang. Pada lirik nglimpang segane dadi sak latar menggambarkan suatu akibat dari bencana hukuman tersebut yang dapat berefek pada orang disekitarnya seperti keluarga, teman, dan masyarakat.

Adi Deswijaya, S.S., M.Hum menyatakan bahwa makna dari gundhul yakni orang yang tidak mempunyai kemuliaan. Pacul diartikan sebagai alat untuk mencari nafkah karena dilihat dari fungsi pacul yaitu mencangkul sawah. Gembelengan artinya sikap yang jelek seperti sombong, congkak, tinggi hati, dan berbuat seenaknya sendiri. Nyunggi maksudnya kalau mengerjakan sesuatu harus sungguh-sugguh, tidah boleh lalai, karena kalau lalai atau tidak hati-hati akan jatuh. Wakul di sini menyangkut tentang keuangan yang mencari nafkah. Nyunggi wakul berarti melakukan sesuatu yang berhubungan dengan keuangan harus berhati-hati dan kalau lalai bisa terjatuh. Gembelengan artinya sikap yang jelek seperti sombong, congkak, tinggi hati, dan berbuat seenaknya sendiri. Orang yang melakukan perbuatan buruk seperti sombong, congkak, tinggi hati, dan berbuat seenaknya sendiri akan berkaibat pada dirinya sendiri yakni orang tersebut akan jatuh dari kemuliaan atau kehormatannya. Wakul nglimpang dapat digambarkan sebagai orang yang tadi melakukan perbuatan buruk seperti sombong, congkak dan tinggi berakibat pada dirinya sendiri yakni orang tersebut dijatuhi balasan dengan menjatuhkan orang tersebut dari tahta atau kemuliaan yang efeknyadapat dirasakan oleh dirinya sendiri dan orang di sekitarnya, hal tersebut digambarkan pada nglimpang segane dadi sak latar.

Ketiga informan dalam pemaknaan makna budaya lirik lagu dolanan "Gundhul Pacul" yaitu kata gundhul yakni orang yang kehilangan kemuliaan atau kehormatan karena gundhul berarti kepalanya plontos (tidak mempunyai rambut). Pacul maksudnya mencari penghasilan 
untuk hidup karena fungsi pacul sendiri yakni untuk menvangkul tanah baik di sawah maupun di ladang. Gembelengan artinya suatu sikap yang buruk seperti sombong, berbuat sesuka hatinya sendiri tanpa peduli orang disekitarnya, dan congkak hati. Nyunggi artinya membawa sesuatu yang tidak boleh disepelekan dan harus berhati-hati dalam membawanya. Wakul berarti suatu hal yang menyangkut tentang keuangan. Jadi dapat disimpulkan bahwa nyunggi wakul yaitu dalam mengurus suatu keuangan harus berhati-hati, cermat, tiak boleh lalaui untuk berhura-hura supaya tidak sia-sia dalam pekerjaannya. Gembelengan artinya suatu sikap yang buruk seperti sombong, berbuat sesuka hatinya sendiri tanpa peduli orang disekitarnya, dan congkak hati. Orang yang bersikap buruk pada orang kain dan mempunyai sifat sombong dan congkak hati, suatu saat akan mengalami hal yang fatal atau yang tidak menguntungkan pada dirinya sendiri. Wakul nglimpang digambarkan sebagai orang yang tadi melakukan perbuatan buruk seperti sombong, congkak dan tinggi berakibat pada dirinya sendiri yakni orang tersebut dijatuhi balasan dengan menjatuhkan orang tersebut dari tahta, kemulaian, kehormatan yang efeknya dapat dirasakan oleh dirinya sendiri dan orang di sekitarnya seperti keluarga, teman, dan masyarakat sekitar, hal ini diilustrasikan pada nglimpang segane dadi sak latar.

\section{SIMPULAN DAN SARAN}

Lagu dolanan di Jawa Tengah seperti dhondhong apa salak dan gundhul paculi mempunyai makna budaya yang dalam baik pada pendidikan dan kehidupan anak-anak. Dari pembahasan di atas dapat disimpulakn bahwa lagu dolanan dhondhong apa salak mempunyai makna budaya yakni karakter manusia ada 3 diilustrasikan seperti buah dhondhong, salak, dan duku. Sifat yang paling baik diantara ke tiga ilustrasi tersebut yaitu buah duku karena sifat luar dan dalam sama-sama baik, halus, dan lembut. Seorang anak itu harus berbakti, berperilaku baik, dan tidak membantah kepada orang tua, nanti orang tua akan memberikan penghargaan atau hadiah kepada anaknya.

Lagu dolanan Gundhul Pacul mengandung makna budaya yaitu jika orang yang mempunyai kehormatan, kedudukan, dan kemuliaan karena mempunyai penghasilan yang luar biasa, maka janganlah menjadi sombong, tinggi hati, dan congkak karena kalau orang tersebut melakukan hal-hal yang mengarah negatif maka orang tersebut akan dihajar hukuman oleh Allah dengan cara menjatuhkan kehormatan, kedudukan, dan kemuliaan orang tersebut serta kekayaannya akan musnah, sehingga orang tersebut dan mungkin bisa menjalar kepada orangorang disekitarnya akan merasakan kerugian yang mendalam.

Lagu dolanan pada umumnya di pulau Jawa, pada khususnya di Propinsi Jawa Tengah, harus dipertahankan pada zaman modern ini karena lagu dolanan Jawa sekarang mulai tergerus akan lagu anak-anak modern yang berbahasa Indonesia yang isi lirik lagunya kebanyakan mengandung tentang percintaan antara anak laki-laki dan perempuan. Penulis berharap kepada guru bahasa Jawa di TK, SD, dan SMP bisa menerangkan makna budaya yang terdapat pada lagu dolanan Jawa, tidak hanya pada hafalan lagu dolanan saja, tetapi agar anak-anak bisa memahami betul makna budaya Jawa.

\section{DAFTAR RUJUKAN}

Abdullah,W. (1999). Bahasa Jawa Dialek Masyarakat Samin di Kabupaten Blora (Laporan Penelitian Dasar), Surakarta, Fakultas Sastra dan Seni Rupa.

Dibia, I,W. (2000). Revitalisasi lagu anak-Anak Diperlukan, Warta Kota 7 September, Direktorat Jenderal Kebudayaan: Seksi Dokumentasi Subdit Dokumentasi dan Publikasi 
Direktorat Nilai Estetika.

Foley, W,A. (1997). Antropological Linguistics, Massachusetts, Blackwell Publisher.

Kridalaksana, H. (2011). Kamus Linguistik, Jakarta, PT Gramedia Pustaka Utama.

Pateda,M. (2001). Semantik Leksika, Jakarta, PT. Rhineka Cipta.

Scheaffer,R.L, Mendenhali,W,danOtt, L. (1990). Elementary Survey Sampling, Amerika, PWS-KENT Publishing Company.

Subroto,E. (1992). Pengantar Metoda Penelitian Linguistik Struktural, Surakarta, Sebelas Maret University Press.

Suciati, S. (2001). Ideologi Gender dalam Lagu Dolanan, Semarang, Balai Bahasa.

Supanto, dkk. (1982). Sejarah dan Budaya (Seri: Folklore), Balai Penelitian Sejarah dan Budaya Yogyakarta.

Sutopo, H.B. (2006). Metodologi Penelitian Kualitatif, Surakarta, Universitas Sebelas Maret Press.

Suyani. (2012). Makna Filosofis Dalam Lagu-Lagu Dolanan Jawa: Kajian Serat Rarya Saraya', Jantra, Vol. VII, No. 2, Desember 2012, pp. 204-223.

Widodo, S. (2001). Gendhing-Gendhing Dolanan, Sukoharjo: CV. Cendrawasih. 